Fecha de recepción: abril 2020

Fecha de aceptación: mayo 2020

Versión final: junio 2020

\section{El siglo XXI: la curaduría como el boom del momento y los libros específicos}

Eugenia Garay Basualdo ${ }^{(1)}$

Resumen: a partir de la década de 2000 se editan las primeras, pero escasas, publicaciones físicas en formato de libro sobre la curaduría local. Un momento en el surgen nuevas instituciones dedicadas al arte contemporáneo y en consecuencia nuevas colecciones; un marco en el que la figura del curador, aunque todavía es protagonista de polémicas, se consolida tanto en el ámbito institucional como en el independiente. Este trabajo analiza las publicaciones específicas sobre curaduría surgidas entre 2002 y 2017 en la Argentina desde un enfoque crítico, e intentan ser un aporte para una apreciación de los avances en los estudios sobre la curaduría a nivel local.

Palabras clave: estudios sobre curaduría - historia de las exposiciones - práctica curatorial.

[Resúmenes en inglés y portugués en las páginas 72-73]

(1) Magíster por la Universidad Nacional de las Artes y magíster por dicha institución en el área de Crítica y Difusión de las Artes.

\title{
Introducción
}

En el campo del arte argentino contemporáneo la curaduría se instala como práctica, y crece de manera paulatina, a partir de la década de 1980. Sin embargo, su estudio teóricocrítico como disciplina se inicia en el país recién a comienzos del siglo XXI. De esta forma, comienza a crearse un nuevo campo de investigación con una dinámica propia. En los 2000 con el surgimiento de nuevas instituciones dedicadas al arte contemporáneo y, de nuevas colecciones, la figura del curador se consolida institucional como independientemente. En este contexto distintas instituciones y universidades empiezan a editar las primeras publicaciones físicas en formato de libro sobre la curaduría local. Con el pasar de los años y, contando con los avances de la tecnología, se suman algunas revistas electrónicas que desarrollan en parte los estudios curatoriales. En principio se publican compilaciones de entrevistas y de conferencias que, en su mayoría, responden a experiencias de curadores llevadas a cabo en el país y en el exterior. No obstante, con respecto a los estudios sobre la historia de las exposiciones pueden reconocerse dos vertientes de análisis: por un lado, los 
estudios nucleados en el campo de la historia del arte, en los que se menciona y/o aborda particularmente a algunas exhibiciones; $y$, por otro lado, los estudios curatoriales con sus objetos y temáticas específicas, lo que deviene en la historia de la curaduría. Es entonces que las publicaciones que aquí se estudian se diferencian entre las que produce el Grupo de Estudios sobre Museos y Exposiciones ${ }^{1}$, basadas en las jornadas sobre las exposiciones que organizan en cuatro ocasiones, y otros libros que contienen conferencias y ensayos, algunos sobre casos y otros con disquisiciones teóricas sobre la curaduría. Se intenta seguir un esquema cronológico, y se decide incorporar información sobre las carreras de curaduría y sus publicaciones físicas y electrónicas porque, a la vez de aportar contenidos, posibilita visibilizar el estado en el que se encuentran las diferentes áreas de investigación de las instituciones. Sin embargo, de ningún modo este estudio aspira a convertirse en una genealogía porque es ciertamente incompleto y excluye publicaciones por una cuestión de extensión, de las que igualmente se da cuenta.

\section{El GEME: grupo de estudios sobre museos y exposiciones}

En el año 2002 se conforma el GEME integrado por Fabiana Serviddio, Mariana Marchesi, Cecilia Rabossi y Viviana Usubiaga, con la dirección de Andrea Giunta y María José Herrera, y con asiento en el departamento de investigación del MNBA. El grupo empieza a trabajar con un subsidio de la Fundación Antorchas y, como apunta Herrera en la primera publicación, su labor "consistió en relevar e investigar las exposiciones de cada década en las principales instituciones públicas de Buenos Aires entre 1955 y 2006” (Herrera, 2009, p. 10) para conformar una base de datos y profundizar en el estudio de una exposición determinada, con la idea de presentar estos estudios en encuentros sobre la temática ${ }^{2}$. Para mayo de 2006 el GEME organiza las Primeras jornadas sobre exposiciones de arte argentino 1960-2006 en y con la colaboración del MNBA, además de la Dirección Nacional de Patrimonio y Museos. Éstas proponen partir de la premisa de que "las exposiciones son un instrumento privilegiado para la administración de los significados del arte" (2009, p. 10) y llaman a la reflexión sobre las tendencias curatoriales y las políticas culturales que éstas implican, estudiando diversos tipos de exposiciones, con la intención de verificar la circulación de los discursos teóricos y artísticos, sus relaciones y sus formas de comunicación. A la vez, el grupo incentiva el intercambio entre curadores, historiadores e investigadores de Buenos Aires, La Plata, Rosario y Córdoba. En el mes de julio de 2009 el GEME publica su primer libro en el que se conocen los trabajos de sus integrantes y una selección de ponencias de las jornadas que realizan en 2006. Con el título Exposiciones de arte argentino 1956-2006. La confluencia de historiadores, curadores e instituciones en la escritura de la historia ${ }^{3}$ la publicación cuenta con veintidós artículos ordenados según cuatro tópicos: I. Instituciones y políticas curatoriales; II. Las exposiciones como institución del campo artístico; III. Las estrategias curatoriales: del guión científico a la instalación museográfica; y IV. La voz del curador. También suma un apéndice denominado políticas culturales y un listado de las muestras realizadas en el MNBA y con su patrimonio en otras instituciones entre 1956 y 2006. En el prólogo Herrera, además de referirse a la constitución del grupo 
y sus objetivos, y de anunciar la selección de ponencias que integran el libro, siendo las del GEME sobre el MNBA y sus políticas culturales y curatoriales, pone énfasis en definiciones fundamentales como qué es la curaduría, qué es una exposición y cuál es el rol del curador. A esta altura tal vez parezca irrelevante aclarar de qué se tratan estos conceptos, pero para el año 2009 resulta un aporte por escrito, quizás por primera vez en una publicación local en formato físico, que resulta significativo para clarificar el alcance de la profesión. De hecho, la curadora cierra la introducción señalando que tanto las jornadas como la publicación proponen discutir acerca de la práctica del curador como mediador “entre la investigación pura y los códigos de representación de la museología” (2009, p. 12). En septiembre de 2009 el GEME lleva a cabo las segundas jornadas ${ }^{4}$ sobre exposiciones en Córdoba. Para ese entonces, el grupo continúa sólo bajo la dirección de Herrera, sumándose desde el departamento de investigación del MNBA Patricia Corsani, María Florencia Galesio y Paola Melgarejo. En abril de 2011 se publica el segundo volumen de su trabajo denominado Exposiciones de arte argentino y latinoamericano. Curaduría, diseño y politicas culturales ${ }^{5}$. Los tópicos que agrupan a los veintitrés artículos son: I. La exposición como institución del campo artístico; II. Curaduría, museos y políticas culturales I; III. Curaduría, museos y políticas culturales II. Instituciones en Córdoba; y IV. Estrategias y modelos de curaduría. Al parecer el tópico instituciones y políticas curatoriales del primer libro pasa a llamarse curaduría, museos y políticas culturales en el segundo, a la vez que la voz del curador se convierte en estrategias y modelos de curaduría. En el prólogo Herrera reflexiona acerca de la exposición como un medio para tratar al arte "como un objeto semiótico que necesita ser decodificado y recodificado para su comunicación” (Herrera, 2011, p. 9), al mismo tiempo que se refiere al anclaje institucional nunca neutro de una exposición como paratexto al texto de la propia muestra. Además, indica que desde la conformación del GEME trabajan en dos modalidades: la del abordaje de exposiciones históricas introduciendo información edita e inédita a través del rescate, la conformación y divulgación de archivos, y la que denominan la voz del curador que implica reflexionar sobre la práctica en primera persona aportando cuestiones que sobrepasan las posibilidades de un catálogo u otro formato, convirtiéndose en un testimonio. La mitad de los trabajos de este tomo están dedicados a exposiciones y/o experiencias curatoriales que tienen lugar en La Plata, Rosario, Córdoba, Posadas y Salta, y que suman una contribución inédita al estudio de este campo. El grupo publica su tercer libro en agosto de 2013 con el nombre Exposiciones de arte argentino y latinoamericano. El rol de los museos y los espacios culturales en la interpretación y la difusión del arte ${ }^{6}$, y contiene veinticinco artículos de una vasta diversidad, producto de las terceras jornadas sobre exposiciones realizadas en el Centro Cultural Parque España de la ciudad de Rosario, Santa Fe, en 2011. La estructuración antes seguida se ve modificada sosteniendo sólo un tópico de las anteriores publicaciones y agregando nuevos: I. La exposición como institución del campo artístico; II. Proyectos curatoriales y de extensión y discusión del arte; III. Exhibiciones y estrategias consagratorias y contraculturales; IV. Políticas culturales en museos y espacios de arte; y V. Exposiciones en la escena artística contemporánea. En la introducción Herrera reseña la historia del GEME a diez años de su conformación, y comenta los enfoques teóricos abordados y su aplicación al estudio de las exposiciones. En este sentido, vale la pena detenerse para mencionar las tres grandes áreas de interés para el grupo que Herrera indica, porque 
actualizan las necesidades de investigación que, en general, tiene este campo de estudio. La primera denominada el museo como ámbito de exhibición está destinada:

$\mathrm{Al}$ análisis de las programaciones de los museos; el estudio de las exposiciones de arte como factor modernizador; la representación del arte argentino en las exposiciones permanentes y temporarias en los museos públicos y privados; la influencia de la dinámica de otras instituciones y espacios de exhibición sobre los museos; la recepción de las exposiciones en la prensa; el público de las exposiciones, su historia, estudio y evaluación; y el rol educativo del museo y sus exposiciones (Herrera, 2013, pp. 11-12).

La segunda, llamada las exposiciones como instituciones del campo artístico, se basa en el estudio de los diversos formatos como salones, premios, bienales, entre otros, y su historia y recepción; y además, la relación entre las exposiciones y el mercado del arte con el surgimiento de las ferias a fines de los ochenta en el país. Una tercera área designada como estrategias curatoriales. De la hipótesis al guión científico propone estudiar guiones y otros textos curatoriales como estrategias discursivas y su relación con el contexto disciplinar y sociopolítico. Asimismo, Herrera aclara que dentro de este área se incluye "la relación entre curaduría, conservación y documentación” (2013, p. 12) a fin de abordar las polémicas que se producen entre "la exhibición de objetos originales, reconstrucciones o recreaciones, los límites de la representación de obras efímeras o destruidas" (2013, p. 12), y el uso de los documentos. Esta recapitulación de las intenciones del GEME está acompañada por un análisis crítico sobre el estudio de los museos con el título museos, historia y sociología, y dos apartados más dedicados a comentar algunos artículos de las tres publicaciones referidos tanto al MNBA como a exposiciones paradigmáticas que se llevan a cabo en otras instituciones. La cuarta y última entrega de la serie del GEME se publica como dossier digital en el primer semestre de 2017 en la revista CAIANA ${ }^{7}$ con el título Historias de exposiciones y sus instituciones: un abordaje complejo de las instancias de significación del arte, las apropiaciones interpretativas de los objetos y sus distintos relatos a través de la historia. En el prólogo Herrera focaliza en explicar el rol del museo dentro de la educación no formal y sus posibilidades, y dedica unos párrafos a la publicación como resultado de las cuartas jornadas sobre exposiciones que se efectúan en la sede de la Universidad Nacional de Tres de Febrero sita en el Centro Cultural Borges en agosto de 2013. La propuesta del grupo para estas jornadas es la de "reflexionar acerca del modo en que, a lo largo de su historia y como parte de la iniciativa de los estados, los museos contribuyeron a construir y sostener la nación, su prestigio e identidad a través de la exhibición de sus tesoros patrimoniales" (Herrera, 2017, p. 96). En esa consideración acerca del lugar que ocupa un museo, que se puede entender como aparato de estado siguiendo a George Didi-Huberman ${ }^{9}$ para accionar con el público, Herrera localiza al curador como mediador "entre el conocimiento propio de su práctica (la historia del arte, la teoría, la interpretación) y las diversas instancias políticas, económicas y sociales entre las que actúa" (2017, p. 96) La curadora define el área de estudio de las cuartas jornadas mencionando que se dedican a discutir sobre: 
Las distintas prácticas que un curador pone en juego en los relatos que elabora en torno a los objetos que exhibe. Debatimos acerca de cuál es su responsabilidad y aporte a la escritura de la historia del arte a través de las exposiciones; la ética de su labor inmersa en los diálogos y disputas surgidos de las complejas relaciones entre las instituciones y las prácticas artísticas que interactúan en el campo cultural argentino y latinoamericano (2017, p. 97).

Sin tópicos preestablecidos como en las ediciones anteriores, Herrera comenta diez de los dieciséis artículos del dossier. Si bien los aportes son por demás significativos, este último volumen del GEME no posee investigaciones de sus integrantes salvo la introducción de Herrera. Al mismo tiempo, revela un tono crítico apuntando a poner en jaque el rol de las instituciones estatales en cuanto a la producción de exposiciones, y al del curador en tanto artífice de las mediaciones que puede protagonizar, y que no necesariamente coopera con la consolidación de la profesión, dado que se pueden desdibujar sus límites y responsabilidades. En síntesis, los aportes del GEME abren el campo del estudio teórico sobre la curaduría a nivel local, estableciendo nuevas áreas de investigación y promoviendo el cruce entre historia del arte, curaduría y el abordaje académico para aplicarlo a la elaboración de una historia de las exposiciones para nuestro país y, en ocasiones, para Latinoamérica.

\section{El marco teórico que sigue el GEME}

En la producción escrita de la historiadora de arte, curadora y crítica María José Herrera puede encontrarse, además de sus investigaciones sobre casos específicos, un corpus teórico sobre la curaduría basado en los estudios que realiza en los noventa y en su vasta experiencia como investigadora y curadora en el MNBA, en el Museo de Arte Contemporáneo de la Ciudad de Buenos Aires y en el Museo de Arte de Tigre, además de su actividad independiente. Como lo expresa en la introducción de la primera publicación del GEME:

La estadía en la Universidad de Texas en 1996 y, posteriormente una beca de la Fundación Antorchas-Lampadia en la National Gallery de Washington, me hicieron ver la importancia de lo que en el ámbito anglosajón se llama los $\mathrm{Mu}$ seum Studies: una rama de estudios acerca de los museos no solamente desde una perspectiva empírico-técnica, museológica, sino también un tipo de reflexión histórica y sociológica acerca del impacto de los museos y las exposiciones en la representación del arte y la cultural en general (Herrera, 2009, p. 10).

Es así que en los cuatro prólogos y en varios textos que Herrera escribe y es co autora para las publicaciones del GEME se pueden observar nociones y definiciones a través de las que aborda el campo curatorial local, y a la vez, terminología técnica específica que da cuenta del tipo de análisis científico que propone en sus investigaciones. En la presentación del primer libro del GEME parte de preguntas como "¿Qué racionalidad está en la base de las exposiciones? ¿Qué tipo de conocimiento transmiten los museos a través de sus distintos 
modelos de exhibición?” (2009, pp. 9-10). Para poder responder a estos cuestionamientos advierte que hay que analizar las políticas de exhibición y el accionar de quienes las llevan a cabo. Es así que se refiere a la importancia de las exposiciones que, por su complejidad de producción y gestión, son formatos sofisticados de comunicación. Las llama puestas en escena "de distintos saberes e implica una verdadera construcción de sentidos" (2009, p. 9), como también que son "el resultado de una interpretación, y el responsable de dicha interpretación es el curador" (2009, p. 9). Señala a la curaduría como una práctica de mediación que puede provenir de distintas perspectivas como la historia del arte o la estética en el caso de las exhibiciones de arte, y al curador como una figura que emerge a mediados del siglo XX con gran un predominio, cuyas tareas son concebir una idea, investigar, coordinar y poner en escena una exposición. En la actualidad, polémicas de por medio, su rol "resulta protagónico en exhibiciones que se proponen como ensayos de autor" (2009, p. 9). Una definición de Herrera que resume las funciones de un curador es la de "mediador, autor, escritor, re - escritor o intérprete, el curador es el encargado de los aspectos conceptuales de una exhibición y de su forma de comunicación, de la construcción discursiva que esta plantea" (2009, p. 9). En el prólogo del segundo libro del grupo, Herrera reafirma el abordaje de trabajo diciendo que:

Estudiar las exposiciones no es sino enfocar a la obra de arte inmersa en un contexto, en otro discurso. Un discurso externo, que se suma al del productor y que permite ampliar la consideración acerca de la representación, la circulación y la recepción del arte en una época dada (Herrera, 2011, p. 10).

Nuevamente sobre las bases de los museum studies y sumando autores del campo cultural como Raymond Williams, Pierre Bourdieu y Michel Foucault indica que la perspectiva del grupo "se sitúa en el análisis de las exposiciones como instituciones, organizaciones fundamentales para el conocimiento y difusión del arte" (2011, p. 10). En la introducción del tercer volumen del GEME, Herrera desarrolla una sección titulada museos, historia y sociología, en la que trabaja conceptos sobre los museos de autores como Tonny Bennet ${ }^{10}$ y Eilean Hooper Greenhill ${ }^{11}$ que a la vez toman nociones de Michel Foucault ${ }^{12}$, otros de Douglas Crimp ${ }^{13}$ que cita a Antonio Gramsci, e incorpora definiciones de Carol Duncan ${ }^{14}$ y George Didi-Huberman ${ }^{15}$. Es así que aborda el nacimiento del museo moderno y sus antecedentes como las ferias itinerantes, las exposiciones industriales, las tiendas departamentales y los parques de entretenimientos como aquellos que "desarrollaron y practicaron el exhibir y el mostrar, propio de los museos" (Herrera, 2013). Reflexiona sobre la eficacia de los museos y su influencia en la contemporaneidad gracias a las exposiciones como "eventos colectivos que desde tiempos remotos combinan modelos de interacción social, presentes en la dinámica del museo moderno" (2013, p. 13). Pero al mismo tiempo se refiere al modo de control social que ejerce un museo sobre una comunidad. Siguiendo a Foucault la autora apunta que:

Cada momento histórico desarrolló una episteme distinta, entendiendo por episteme al "conjunto de relaciones inconscientes pero productivas dentro del cual se produce el conocimiento y se define la racionalidad". Dicha episteme se 
muestra como la congruencia que, a gran escala, existe en la actividad intelectual de cada período. Así, de las maravillas de los "gabinetes de curiosidades" medievales, a las clasificaciones analógicas o el modelo organicista de la modernidad decimonónica, el museo ha reflejado las distintas epistemes con la que construye la legitimidad de lo que exhibe (2013, pp. 14-15).

Además, entabla una discusión entre autores que manifiestan que los museos son instituciones que articulan relaciones de poder según Crimp, o disciplinarias y de confinamiento conforme Foucault, y que priorizan la exhibición por encima de sus otras funciones poniendo en escena objetos y sujetos como forma de poder como propone Bennett. A esto cruza con una expresión de Carol Duncan sobre el museo nacional como el custodio de la herencia cultural de una sociedad, y otra de Didi-Huberman que señala al museo como un aparato de Estado que exige centralismo y territorializa versus la exposición como máquina de guerra, asociada al nomadismo y la desterritorialización. Cierra sosteniendo que:

La dialéctica entre museo y exposición, plantea variados puntos de abordaje para el historiador. Desde la perspectiva de la historia institucional y la inserción de las poéticas en su seno, el estudio de las exposiciones permite reconstruir las políticas culturales y sus alcances (2013, p. 17).

En la presentación de la cuarta y última publicación del GEME, Herrera propone pensar al museo como un centro de una educación no formal, en el que las exposiciones y las posibles selecciones o recortes de objetos a exhibir constituyen las discursividades de la institución. La autora recupera el leiv motiv de las últimas jornadas del grupo basadas en reflexionar acerca de cómo los museos por iniciativa de los estados contribuyen a construir la identidad y el prestigio de una nación mostrando su patrimonio, y agrega que "el diálogo intercultural que el museo permite lo constituye en un verdadero ámbito de competencia simbólica más allá de lo artístico [y que] distintas coyunturas locales han replanteado la relación entre lo público y lo privado en estas instituciones" (Herrera, 2017, p. 96). En este punto advierte críticamente que "museos, ferias y bienales, establecen valores casi en forma equivalente, desdibujando los límites entre la representación cultural y la mercantilización del arte" (2017, p. 96). En este marco el curador se impone dado a que suele convertirse en "árbitro de las relaciones de la cultura, entre las instituciones y las agendas políticas y de mercado" (2017, p. 96). Vuelve sobre su definición de curador como mediador pero esta vez la amplía señalando que opera entre su conocimiento propio de la práctica y las distintas instancias políticas, económicas y sociales entre las que actúa. De esta manera, en las últimas jornadas discuten sobre la responsabilidad y el aporte del curador a la escritura de la historia del arte a través de las exposiciones, y sobre "la ética de su labor"16 que se encuentra en medio de los diálogos y las disputas de las relaciones entre las instituciones y las prácticas artísticas. Herrera reafirma que el trabajo del GEME propone un cruce entre los museum studies, la historia de las instituciones y las exposiciones, y rescata que una contribución del grupo es "estudiar y evidenciar la representación del arte argentino en las exposiciones permanentes y temporarias en los museos públicos” (2017, p. 97). En particular del MNBA el grupo se ocupa de analizar las diversas gestiones desde 
su fundación hasta la actualidad para "establecer qué modalidades expográficas fueron puestas en juego en cada una de las sucesivas sedes del MNBA, y en los relatos implícitos en sus curadurías" (2017, p. 97). Un rasgo estudiado en varios de los trabajos del grupo y que Herrera corrobora en este prólogo es el de cómo a través de la legitimación de ciertas poéticas en la institución se pueden reconstruir las políticas culturales y sus alcances. Es por esto que se dedican a analizar las estrategias curatoriales a partir de los guiones y otros textos producidos por los diversos curadores. Aquí la autora destaca que este tipo de análisis lleva a prestar particular atención a la relación entre curaduría, conservación y documentación.

\section{La línea de trabajo del GEME: el estudio de la historia curatorial del Museo Nacional de Bellas Artes}

Como señala María José Herrera las investigaciones del grupo se basan en el cruce entre los museum studies, la historia de las instituciones y las exposiciones, y dedican sus trabajos a reconstruir las políticas culturales y curatoriales puestas en funcionamiento en el MNBA. En una sección denominada la historia del MNBA a través de sus archivos del prólogo del tercer libro del GEME, Herrera traza una cronología abreviada de la historia curatorial del museo comentando los estudios que el grupo y otras colegas realizan en el transcurso de diez años. Intercala acotaciones que posibilitan la comprensión de una historia integral de la institución e incorpora cuestiones propias de la curaduría que surgen del rescate de los archivos curatoriales del MNBA en el año 2000. Por ejemplo, en referencia al criterio del primer montaje de obras en el museo que lleva adelante Eduardo Schiaffino, el primer director, en el que implementa el ordenamiento por géneros dado que aún la colección no cuenta con piezas suficientes para una distribución por escuelas, la autora define que "este criterio dejaba en evidencia la formación de Schiaffino como artista y su habilidad de curador para encontrar un orden posible al pequeño universo al que le tocaba dar sentido. Efectivamente, consideramos a Schiaffino el primer curador del arte argentino" (Herrera, 2013, p. 18). En cuanto al trabajo del GEME y la pesquisa que llevan adelante en el archivo del MNBA y en otros complementarios, Herrera indica que logran "reconstruir en parte los primeros guiones curatoriales y analizar las modalidades de exhibición a principios del s. XX" (2013, p. 18). Y como metodología estudian por década la instalación de la colección permanente teniendo en cuenta las adquisiciones que se van produciendo a lo largo del tiempo. Además, explica brevemente las gestiones de los tres directores que le siguen a Schiaffino y los cambios de sede que sufre el museo hasta ser instalado en la ubicación actual en 1932. No obstante, hay períodos que no están trabajados de manera exhaustiva: la dirección de Schiaffino (1896-1910) cuenta solamente con un artículo que trata las adquisiciones que realiza en 1906 y sus planteos curatoriales; el tramo histórico 1911-1943 no aparece en las publicaciones del grupo pero si está desarrollado por Herrera en el libro Travesías de la Imagen II; el lapso 1944-1955 no se encuentra enteramente estudiado salvo por un texto de la cuarta publicación del GEME que aborda la exposición de 1952-1953 La pintura y la escultura argentinas de este siglo. Otras etapas pendientes de estudio son: 1994- 
2003 mandato de Jorge Glusberg, 2007-2013 a cargo de Guillermo Alonso, y 2013-2015 con Marcela Cardillo como directora interina. No obstante, éstas se hallan desarrolladas por Herrera en el ensayo El Museo Nacional de Bellas Artes: historia, gestiones y curaduría que forma parte del catálogo razonado publicado en 2010. Sin embargo, también puede considerarse como complemento a estos saltos temporales en la historia del MNBA el tratamiento que María José Herrera dedica al museo, desde su fundación hasta mediados de los dos mil, en su libro Cien Años de Arte Argentino publicado en 2014.

\section{Libros sobre curaduría en formato físico}

\section{Gumier Maier, J. (Ed.). (2005). Curadores. Entrevistas}

En el ámbito local se estima que el libro Curadores. Entrevistas, que se publica en 2005, es una de los primeros. En su prólogo, el compilador Jorge Gumier Maier ${ }^{17}$ señala que "no están todos los que son ni son todos los que están, pero hemos intentado cubrir un panorama amplio y variado" (Gumier Maier, 2005, p. 5). Y si bien es una publicación precursora para este campo de estudio, también son notables las ausencias como la del propio Gumier Maier, entre otros curadores activos en ese momento. Sin embargo, reúne treinta y dos entrevistas realizadas a treinta y cinco curadores provenientes de la historia del arte como Valeria González o Adriana Lauria, o artistas - curadores como Leo Battistelli o Alberto Goldenstein, o curadores independientes como Rodrigo Alonso, o curadores institucionales como Laura Buccellato. El conjunto de reportajes congrega experiencias curatoriales llevadas a cabo dentro y fuera del país, transformándose en testimonios de época insoslayables a la hora de abordar la curaduría desde los ochenta en adelante, y que revelan distintos aspectos de la tarea del curador. A modo de rescate de alguna de estas, se pueden mencionar las efectuadas a Andrés Duprat y a Fernando Farina, en las que ambos comentan sus gestiones al frente de museos, y en las que se puede apreciar los criterios de conformación de colecciones de arte contemporáneo; o, las de Sonia Becce y de Victoria Noorthoorn habiendo estudiado curaduría en el extranjero e iniciando sus carreras con la realización de exposiciones en diversos países. Gumier Maier indica: “optamos por solicitarle a cada quien que diera cuenta de su labor, y por eso la pregunta sobre cómo devinieron curadores fue siempre la que inició el diálogo" (Gumier Maier, 2005, p. 5). En función de este disparador y analizando cada contestación se distinguen los alcances en la práctica de cada entrevistado. En este sentido, se pueden resaltar algunas reflexiones en torno al quehacer individual y a lo que piensan sobre la curaduría y el rol del curador para ese entonces. A continuación se transcribe una selección aleatoria, aunque tiene en cuenta un amplio rango etario y de ocupación de base del entrevistado/a. Fragmento del diálogo con Laura Buccellato ${ }^{18}$ :

-Fuiste curadora antes de que la palabra estuviese en circulación, de espacios y muestras muy diferentes...-Hay distintos tipos de curador: uno es el curador 
de una exposición puntual, otro es el curador de una colección y otro el de una institución. En mi caso, a veces tengo que hacer las tres cosas." (Buccellato, 2005:121)

Andrés Duprat ${ }^{19}$ :

Creo que el trabajo de un curador es proponer lecturas interesantes sobre las producciones artísticas. Se trata de la construcción de un relato a partir de obras de arte. Y los abordajes son infinitos: dar a conocer, relacionar producciones, asociar, confrontar, poner en contexto, hacer nuevas lecturas, para eso hay que conocer en profundidad el campo en el que se opera. El trabajo del curador tiene que ver con el conocimiento y con la sensibilidad (Duprat, 2005, p. 172).

Marcelo Pacheco ${ }^{20}$ :

Cada vez que se habla de curaduría insisto en que me interesa la práctica curatorial. No pensar a curaduría sino la práctica curatorial, con lo que esto significa a partir de los años ochenta. Un campo de acción al que se vuelcan muchísimas disciplinas, no solamente la historia del arte (Pacheco, 2005, p. 322).

Adriana Lauria ${ }^{21}$ :

Hay una cosa que es cierta y que todos los curadores sabemos y es que tenemos que ocuparnos de que haya un buen catálogo de la muestra, que es lo que nos queda. El evento de la muestra en sí mismo es efímero (Lauria, 2005, p. 292).

Fabián Burgos 22 :

La palabra "curador" es algo que apareció hace poco. No sé muy bien qué significa. Para mí, es como un organizador, pero sospecho que es más que eso. Acá no existe una carrera de curador...pero no es que yo crea que porque esté legitimizado institucionalmente sea importante, en eso también tengo mis reservas (Burgos, 2005, p. 129).

Rafael Cippolini ${ }^{23}$ :

Ser curador, como ser cualquier otra cosa, comienza con una interpelación. En mi caso, esta interpelación me fue dirigida por Ruth Benzacar, que me propuso realizar una curaduría en su galería. Y allí me inventé a mí mismo como curador, para contestar a su llamado y para no ser descortés. Me gustó crearme esa posibilidad, que experimenté como una comunicación rara de mi tarea de escritor. La curaduría, en mi práctica, es una suerte de heteronomía, en el sentido que utilizó Fernando Pessoa para este término. De esta forma se abrió 
una dimensión suplementaria en mi trabajo, que ahora siento tan necesaria como ocasional. No me interesa en absoluto la institución de "curador"; no me interesa la curaduría profesional. Pero se me hace cada vez más imprescindible este proyecto discontinuo que diseño para cada ocasión (de allí lo de ocasional) (Cippolini, 2005, p. 147).

Es así que transitando estas disquisiciones sobre la curaduría y el curador se logra tener un panorama parcial de lo que se considera que conlleva esta práctica para mediados de la década de 2000 en la Argentina.

\section{Alonso, R. (Ed.). (2009). Prácticas curatoriales para las artes tecnológicas: calibran- do - diseñando con textos: Seminario internacional.}

Entre el 30 de septiembre y el 3 de octubre de 2008 en el Espacio Fundación Telefónica ${ }^{24}$ se lleva a cabo el Seminario internacional prácticas curatoriales para las artes tecnológicas. Calibrando / Diseñando Contextos con la coordinación académica de Rodrigo Alonso ${ }^{25}$. En julio de 2009 se edita la publicación bilingüe que, con el mismo título, reúne tres textos de presentación, los ensayos de los curadores extranjeros participantes y sus biografías, y los casos estudiados en las diversas jornadas. Alejandrina D’Elía, gerente de la Fundación, en un breve escrito inicial señala que el seminario:

Tuvo como invitados a reconocidos curadores de arte y tecnología de nivel internacional, quienes expusieron, en diversas mesas temáticas, experiencias laborales, análisis sobre el rol de la curaduría de artes tecnológicas y marcos conceptuales de trabajo en torno a las nuevas prácticas mediales. Asimismo, hubo jornadas dedicadas al estudio de casos, en las que se sumó la participación de referentes locales, y visitas a talleres y galerías de arte, que permitieron a los invitados tener un acercamiento a la obra de artistas nacionales (D’Elía, 2009, p. 9).

Con respecto a los catorce casos presentados, seis son de Argentina, y los restantes de Uruguay, España, Inglaterra, México, Brasil, Colombia, Chile y EE.UU. En particular, los argentinos dan cuenta, parcialmente, del panorama del arte tecnológico en Buenos Aires desde el año 2004 en adelante:

- TecnoEscena, curador Javier Acuña, Centro Cultural Recoleta, 2008.

- Videointervenciones en la ciudad de Buenos Aires, curador Rodrigo Alonso, Edificios públicos de la ciudad de Buenos Aires, 2007.

- Continente, curadores Gabriela Golder y Andrés Denegri, Buenos Aires, desde 2005.

- Exhibiciones de net.art, curador Gustavo Romano, Centro Cultural de España en Buenos Aires, 2004 a 2006.

- Eduardo Kac. Obras vivas y en red, fotografía y otros trabajos, curadora Graciela Taquini, Espacio Fundación Telefónica de Buenos Aires, 2006. 
La excepción, en cuanto a la fecha de realización, la representa: Tres proyectos de gestión con la curaduría de Carlos Trilnick, Buenos Aires; que comenta su trabajo al frente del área audiovisual del Instituto de Cooperación Iberoamericana (ICI), luego Centro Cultural de España en Buenos Aires (CCEBA), entre 1986 y 1993, en la que realiza una programación "exhaustiva" de videoarte argentino y latinoamericano. La introducción a cargo de Rodrigo Alonso es un texto fundamentalmente crítico, en el que primero define lo que entiende por práctica curatorial "como un espacio de producción discursiva, con métodos, herramientas, objetivos y ámbitos de actuación propios” (Alonso, 2009, p. 13), que la desliga de la historia del arte, la crítica, la teoría estética y la museología. Luego, objeta a las exposiciones que, tomando como base la historia del arte, no constituyen nuevas lecturas tendiendo a la reiteración. Polemiza sobre el rol del curador indicando que:

La profesionalización de esta labor, o, más exactamente, su estandarización, la ha llevado muchas veces a desestimar su capacidad analítica y crítica, la única capaz de proveerla de recursos para una verdadera creación discursiva. Con mucha frecuencia vemos, por ejemplo, cómo la formulación curatorial de ciertas exposiciones históricas repite las lecturas desarrolladas por la historia del arte sin proveer ninguna mirada alternativa, ninguna puerta hacia una posible comprensión otra que justifique la intervención del curador. Repitiendo lecturas y, con ellas, posturas e interpretaciones posiblemente cristalizadas o asumidas de manera acrítica, su labor no tiene justificación si no es como garante o refrendador de esos discursos ya consolidados (2009, p. 13).

Sobre la curaduría de arte y tecnología, se refiere al contexto en el que se lleva adelante por aquel entonces, apuntando que las transformaciones tecnológicas no se dan de manera pareja en todos lados, y en este sentido resalta que:

Los artistas que trabajan con tecnología en países donde no se la desarrolla o donde su difusión o penetración social es dificultosa, desigual o problemática asumen -aunque sea de manera implícita- un posicionamiento de ribetes sociales, éticos y políticos. La relación entre arte y tecnología en Latinoamérica se plantea necesariamente en estos términos. Cualquier propuesta de este tipo producida en los países de la región lleva implícitas las tensiones entre el imperativo de la expansión tecnológica y la ineludible realidad de las economías y culturas regionales, derivativas y marginadas (2009, p. 14).

Por otra parte, Alonso apunta que el curador especialista en este ámbito debe ser conocedor de los recursos con los que tiene que trabajar, al mismo tiempo que tiene que optar por una posición en consecuencia, y concluye mencionando que:

¿Cuáles son los estándares que manejamos o pretendemos alcanzar? A veces parece existir un contrasentido entre la precariedad de cierta producción tecnológica y la espectacularidad de su presentación. El caso de la Documenta 11 es paradigmático: cientos de horas de cine y video realizados con escasos recur- 
sos se presentaban utilizando las últimas tecnologías de exhibición y proyección. Su curador se vio sorprendido ante a las críticas que comparaban la exposición con la $\mathrm{CNN}$, cuando su intención había sido exactamente la opuesta, una crítica a los grandes medios de producción de la información a través del rescate de historias y narrativas locales, ocultas, mínimas y particulares (...) la falta de recursos tecnológicos puede no ser una limitación, sino simplemente una realidad; la limitación es querer cumplir unos estándares de presentación internacionales que no se adecuan al contexto específico con el que se trabaja $\mathrm{y}$, posiblemente, tampoco a las piezas que han surgido de ese mismo lugar (2009, p. 17).

\section{Herrera, M. J. (Ed.). (2012). La trastienda del curador: la crítica en la práctica cura- torial. Ciencia y experiencia}

La Asociación Argentina de Críticos de Arte ${ }^{26}$ crea en 2008 el Programa de Formación y Práctica Curatorial (Herrera, 2012, p. 10) por el que organiza una serie de conferencias a lo largo de seis años. La primera tiene lugar en la Fundación Jorge Federico Klemm, en el mes de octubre de 2008, y se denomina Confluencias: el encuentro de la historia del arte y la crítica en la práctica curatorial con la coordinación de María Laura Rosa. Se trata de cuatro encuentros con las curadoras Malena Babino, Adriana Lauria, Cristina Rossi y Ana María Battistozzi; las tres primeras disertan acerca de experiencias de exposiciones propias, mientras que la cuarta se refiere al rol de la crítica y al cruce con la actividad del curador, en línea con los debates del momento, y que la AACA atiende particularmente. Ese primer seminario da origen al ciclo La trastienda del curador que, organizado por la AACA en el Centro de Documentación (CeDIP) del Centro Cultural Recoleta, realiza las ediciones I y II entre abril y mayo del 2009; siempre con la mecánica de que cada curador invitado -sea o no miembro de la AACA- presente alguna de sus curadurías dentro o fuera del país. Disertan: María José Herrera, Horacio Zabala, Cecilia Rabossi, Alberto Giúdici, Victoria Verlichak, Laura Malosetti Costa, Inés Katzenstein y Rodrigo Alonso. María José Herrera, presidente de la AACA señala en el prólogo que "entre la "conferencia" y la "clínica", los distintos encuentros sirvieron para escuchar la voz del curador argumentándose o discutiéndose en un lugar de "figura", cuyo "fondo" está constituido por las instituciones con las que interactúa” (2012, p. 11). Dado a la afluencia de público, entre 2010 y 2012 la AACA ${ }^{27}$ lleva a cabo las ediciones III, IV y V nuevamente en el Centro Cultural Recoleta. Participan en la tercera: Adriana Lauria, Lara Marmor, Máximo Jacoby, María José Herrera y Florencia Battiti; la cuarta es la que se analiza a continuación; y en la quinta intervienen: Andrea Juan, Nancy Rojas, Valeria Keller y Violeta Bronstein, Rodrigo Alonso, Andrea Elías, Graciela Kartofel, Mariela Yeregui y Matilde Marín. La última y sexta edición se efectúa en la galería ArtexArte en 2013 con Victoria Verlichak, Valeria González, y María José Herrera y Mariana Marchesi. En 2012 la AACA y la Fundación Alfonso y Luz Castillo publican el único libro que corresponde a su cuarta edición denominado La trastienda del curador: la crítica en la práctica curatorial. Ciencia y experiencia. En la introducción Herrera se refiere a la misión institucional y apunta que “a principios de los años '70, asomó un debate que 
definió el perfil contemporáneo de la AACA cuando comenzó a discutirse si competía a la función del crítico la organización de exposiciones" (2013, p. 10). Además, traza una breve reseña con aquellas actividades que organiza la emblemática institución a lo largo de su trayectoria, como jornadas y exposiciones llevadas adelante por críticos que en algunas circunstancias asumen el rol de curadores. Esta publicación comprende las conferencias de Cecilia Rabossi, Andrea Wain, Adriana Lauria, Fernando Farina y Jorge Zuzulich. Las tres primeras son testimonios de curadurías, y la de Farina es un relato con precisiones, más específicas que las que da en la entrevista del libro Curadores. Entrevistas de 2005, sobre su gestión frente al Museo Castagnino en el momento en que comienza a generarse la colección de arte contemporáneo que da origen al macro. En cambio, Zuzulich genera un aporte teórico-crítico con el título La curaduría como dispositivo en tensión: entre líneas duras y líneas de fuga. El curador, que se desempeña como docente de estética en diversas universidades, toma conceptos provenientes de esa área y los intenta aplicar a la curaduría, y es así que la vincula con las nociones de dispositivo, heterotopía, historia del arte, reificación y máquina de guerra. En todos los casos se agencia de las definiciones e interpretaciones de estos términos de autores como Foucault ${ }^{28}$, Luckács $^{29}$, Bennett ${ }^{30}$, DidiHuberman $^{31}$, Tejeda Martín ${ }^{32}$, entre otros, a fin de analizarlos en el abordaje de la curaduría en tanto práctica, y de la institución - arte. Así es como opina que "puede entenderse [a] la curaduría como un dispositivo que emerge con un sentido orientador y ordenador de sus producciones que son las exhibiciones" (Zuzulich, 2012, p. 70). En cuanto a heterotopía señala que:

Tanto el museo como la biblioteca, lugares que atesoran objetos, son heterotopías vinculadas al tiempo (...) comparten cierto ideal vinculado a lo clasificatorio y, por ende, al concepto de orden (...) sin lugar a dudas, la exposición comparte este principio. En tanto ésta despliega una narratividad que tiene como eje algún tipo de ordenamiento fundante” (2012, p. 74).

Con respecto a la historia del arte tiene en cuenta varios planteos autorales con respecto al tipo de abordaje de las obras de arte y apunta que "surge en Panofsky la imperiosa necesidad de establecer un sentido que devele el contenido de las imágenes, fundado en el concepto" (2012, p. 76). En línea con esto indica que:

La curaduría institucional responde en términos similares, en tanto articula su narratividad en base a este sentido conceptual que se posiciona por sobre las obras para guiar relaciones que se establecen en el espacio exhibitivo. En estos términos se debate hasta la actualidad, la relación de la curaduría con la historia del arte, ya que ésta última le propicia el fundamento "científico" que le permite a lo curatorial establecer su régimen de verdad (2012, p. 76).

Luego, toma el término reificación y propone críticamente su aplicación a la curaduría:

En algún sentido, la curaduría, en tanto dispositivo vinculado a la historia del arte de corte racionalista, supone un doble efecto reificador. Por una parte, y 
como ya se ha señalado, opera sobre las obras estableciendo para éstas un sentido cosificador, manipulándolas como meras cosas que refieren, con mayor o menor precisión, a las tesis de trabajo que aquella sostiene; por otra, tiene la pretensión de modelar la experiencia del receptor a partir de la narratividad ordenada que pone en el espacio exhibitivo. Ambas lógicas reificadoras están sujetas y son parte fundante del dispositivo curatorial el cual tiene como pretensión, en consonancia con el posicionamiento de la clásica historia del arte, expulsar la inconsciencia de las obras y volverlas objetos de conciencia (Didi-Huberman; $2010^{a}$, p. 154), facilitando por su mediación una aprehensión racional por parte del receptor (2012, pp. 78-79).

Sobre el concepto "máquina de guerra", Zuzulich desarrolla la última sección en la que incluye una breve explicación de su surgimiento en las ideas de Deleuze y Guatari, a través de un esquema que compara las características de esos postulados -máquina de guerra y máquina de sobrecodificación-. Posteriormente, indicando la adopción que de estos hace George Didi-Huberman para su texto-conferencia La exposición como máquina de guerra de 2010, Zuzulich despliega un punteo explicativo de los cuatro términos que trabaja el filósofo francés en su discurso. En modo sintético se rescatan algunas explicaciones de Zuzulich al respecto. En cuanto a dialéctica distingue que:

El desarrollo de una exposición debe ser pensado dialécticamente, pero despojándose de dogmatismos. En este contexto Didi-Huberman apunta que "una exposición es una máquina de guerra, un dispositivo asociado al nomadismo, a la desterritorialización” y, en tal sentido, los “[...] aparatos de Estado están del lado del poder, las máquinas de guerra están del lado de la potencia. Para mi esta oposición es fundamental [...] Una exposición no debe tratar de tomar el poder sobre los espectadores, sino proporcionar recursos que incrementen la potencia del pensamiento" (2012, p. 80).

En tanto que para producción resalta que:

Aquí Didi-Huberman se apropia del pensamiento benjaminiano: "No hay dispositivo de exposición que no sea el resultado de un trabajo de producción, en el sentido que le da al término Walter Benjamin [...] Se trata de un acto político porque es una intervención pública e incluso, si ella misma lo ignora, se trata de una toma de postura dentro de la sociedad" (2012, p. 80).

Sobre el término denkraum, más allá de la comparación con el Atlas Mnemosyne de Aby Warburg, cuyo análisis excede el presente estudio, se considera la definición y la posterior reflexión que Zuzulich rescata de Didi-Huberman: ““[...] significa «espacio para el pensamiento", que es lo que una exposición ha de propiciar". (...) "En el caso de una exposición es el espectador el que, enfrentado a las distintas relaciones posibles que propone esa muestra, debe construir las determinaciones"' (2012, p. 80). Para el concepto de ensayo en relación a una exposición, Zuzulich toma las siguientes citas de Didi-Huberman: 
“[...] es un pensamiento en imágenes, un pensamiento que tiene afinidad con la imagen [...] Un ensayista es alguien que engrana distintas imágenes de modo que saquen a la luz un pensamiento. No hay dogma aquí, sino montaje. El montaje como forma continuamente abierta". (...) "En esto debería consistir una exposición, en un ensayo basado en relaciones entre imágenes que en principio son infinitas, que pueden ser repensadas una y otra vez" (2012, pp. 80-81).

En sus conclusiones el autor mantiene el tono crítico manifestando que la curaduría, y se entiende que también el rol del curador, se encuentran en una "encrucijada" entre "una narratividad ordenada" que se ocupa de la puesta en escena de la historia del arte hegemónica y su espacialización institucional, y "una apertura hacia lo inédito", que implica "restituirle cierto valor de reconocimiento a la obra", entre otras cuestiones que esboza (2012, p. 82). En tal sentido, quizás estas observaciones finales de Zuzulich pueden ser discutidas a través del análisis del artículo publicado también La trastienda del curador denominado Un concepto para un espacio: desplazamientos. De la escultura a la instalación. Arte contemporáneo en $3 D$ de la historiadora de arte, crítica, docente y curadora Adriana Lauria. Se trata de la exposición que cura en 2007 en la Casa de la Cultura del Ministerio de Cultura del Gobierno de la Ciudad de Buenos Aires llamada Desplazamientos. Entre la escultura y la instalación. Lauria comenta al detalle su trabajo en un espacio no convencional para realizar una muestra: el edificio del diario La Prensa que pasa a convertirse en la Casa de la Cultura a mediados de los noventa. Si bien este se caracteriza por las invariantes de la arquitectura francesa de fines del s. XIX, la curadora señala que:

Los subsuelos en donde estaban alojadas las rotativas que imprimían el diario era diferentes; el espacio tenía allí un aspecto fabril, considerando las pasarelas, las vigas de hierro doble $\mathrm{T}$-con las cabezas de los bulones que las unen-, la doble altura de la zona que forma un subsuelo en dos niveles (...) se pensaron y adaptaron para que fueran salas de exposiciones y de espectáculos (Lauria, 2012, pp. 85-86).

Conociendo estas dificultades asume la propuesta de realizar esta exhibición que viene con la consigna de que esté integrada por un corpus de obras de arte argentino contemporáneo; y dado a las especificidades del lugar, decide que se trate de piezas tridimensionales: esculturas, objetos e instalaciones. A partir de este punto, Lauria analiza formal y conceptualmente las veintiocho obras de los veinticinco artistas que participan, iniciando con Algunos oficios (1976) de Víctor Grippo. Apunta que la pieza:

Revaloriza el trabajo manual del hombre: hace referencia a las prácticas del herrero, del horticultor o agricultor, del carpintero, el cantero y el albañil (...) la obra tiene un fuerte anclaje en la noción de ready-made de Duchamp. Pero más que un objeto encontrado en el que gravita el azar, Grippo trabajó buscando el objeto que connota sus ideas (...) se trata de un proceso intelectual de reivindicación del trabajo del artista más allá del gusto (2012, pp. 86-87). 
Ésta no se muestra en Argentina desde los setenta y aparece en esta exhibición como una presencia clave del recorrido ${ }^{33}$. Su análisis minucioso continúa con cada una: obras de distintos materiales, técnicas y dimensiones, que requieren de sistemas de montaje particulares y/o demandan de dispositivos de exhibición especiales; amén de los interesantes comentarios que la historiadora incorpora en algunos pasajes, y que dan cuenta de sus averiguaciones. Dentro de las peculiaridades que posee este texto, que proviene de una conferencia que luego Lauria edita y enriquece con información, es cómo pone de manifiesto el trabajo que el curador debe desplegar en una exposición colectiva que reúne piezas muy diferentes, con requerimientos especiales, y un espacio complejo. Es así que, basándose en el recorrido que plantea en el guión, expone las especificaciones de cada pieza, también incorporando referencias acerca de la gestión curatorial, en lo que ataña a los préstamos de museos públicos, coleccionistas, y artistas:

En dos casos tuve que solicitar que se disminuyera el precio [del seguro], no porque fuera excesivo para la pieza en sí, sino para ajustarnos a la realidad de los fondos disponibles (...) estas son algunas tareas no previstas con las [que] puede encontrarse un curador. No son propias de sus funciones principales, pero en ellas se vuelve necesaria su intervención (2012, p. 90).

Al mismo tiempo, un aspecto relevante es cómo tiene en cuenta la manera en que las obras son expuestas originalmente -cada una en su momento de inauguración- para emplear esos datos en el diseño de montaje. Mención aparte merece el trabajo con el espacio, que siendo lo opuesto al cubo blanco y hallándose en un subsuelo, cuenta con pisos de color negro y vigas de hierro a modo de patio de columnas. Por ejemplo, en cuanto a La portadora de la palabra (2005-2007) de Juan Carlos Distéfano indica:

Para emplazar el conjunto, Distéfano pidió que se neutralizara la fuerte presencia del suelo negro, proporcionándole una superficie de apoyo amplia que no constituyera ni una base tradicional ni un zócalo, sino que mantuviera la continuidad de la línea del piso. Este fue un requerimiento difícil de resolver sin incurrir en costos que excedieran el presupuesto disponible (...) se resolvió utilizar dos placas de fina madera -en ese momento no existía la posibilidad de hacerlo con una sola de gran tamaño-, disimulando la unión con cintas de enmascarar y varias capas de enduído, para finalmente pintarlas de blanco (2012, p. 90).

\section{Las carreras de curaduría y sus publicaciones físicas y electrónicas}

\section{ESEADE - Diálogos entre la historia, la curaduría, el mecenazgo y la investigación}

En el año 2005 el Instituto Universitario Eseade abre la primera carrera con título oficial de curaduría en formato de tecnicatura. En 2009 se convierte en la licenciatura de Curadu- 
ría y Gestión de Arte con la dirección de la curadora Delfina Helguera. Para el 2013 dedica un número de su Revista de Instituciones, Ideas y Mercados (RIIM) a esta carrera con el título Diálogos entre la historia, la curaduría, el mecenazgo y la investigación. Con la coedición y artículos de María Laura Rosa y Malena Babino, cuenta además con otros textos de Natalia March, Delfina Helguera, María Silvia V.S. de Sayús, Maraní González del Solar, por parte de la institución, y Francisca Lladó Pol, Florencia Battiti, Graciela Sarti, e Isabel Tejeda Martín, como invitadas de otras. En el prólogo las editoras, que en ese momento se encuentran al frente de la cátedra Seminario de Curaduría $I^{34}$, apuntan que la sumatoria de trabajos pretende promover el intercambio universitario, a la vez que señalan que:

La creciente actividad curatorial que estamos advirtiendo, tanto a nivel argentino cuanto en el ámbito internacional, da cuenta no sólo de la centralidad de esta práctica sino también de su eficacia como mediadora entre el arte y el público y como productora de nuevas narrativas que se incorporan a la escritura de la historia del arte (Rosa y Babino, 2013, p. 6).

Reflexionan sobre la diversidad de temáticas que contiene el libro, sosteniendo que:

La investigación en historia del arte, en arte contemporáneo, en la conformación de las colecciones o en las prácticas del mecenazgo como paso previo para la curaduría, se impone como una vía ineludible para abordar la escritura curatorial. Es así como esta labor promueve nuevas interpretaciones que si bien se alimentan de la historiografía e historia del arte también la renuevan, estableciendo un diálogo poroso que reaviva este campo disciplinar (2013, p. 6).

Con respecto a esto último que mencionan, citan a pie de página a los tres primeros libros del GEME y a la publicación El montaje expositivo como traducción. Fidelidades, traiciones $y$ hallazgos en el arte contemporáneo desde los años 70 de Isabel Tejeda Martín. Dado que el análisis de la totalidad de estos trabajos excede la extensión del presente, solo se aborda Las exposiciones como formas de discurso. Algunas consideraciones sobre las muestras de arte visuales en los espacios de memoria en la Argentina de Florencia Battiti, curadora del Parque de la Memoria de la ciudad de Buenos Aires. La autora se preocupa por enumerar a las instituciones que se dedican a "la transmisión de la memoria" en el país, y luego propone discutir acerca de cómo son utilizadas las exposiciones para comunicar este tipo de temáticas, resaltando que al hacerlo se efectúa una toma de posición y en consecuencia, un acto político:

No caben dudas de que quienes trazan las políticas institucionales de estos espacios consideran, a pesar de las sospechas que se han cernido sobre él, que el arte se ha constituido en una vertiente más del trabajo sobre la memoria social (...) pero el arte -es decir, las obras, los proyectos artísticos elaborados y realizados por los artistas- es habitualmente expuesto a las diversas audiencias que concurren a estos espacios en el marco de "exposiciones", un formato que a mi entender no ha sido objeto de suficiente análisis y reflexión por parte de 
quienes elaboramos los programas de exposiciones y políticas de este tipo de instituciones (...) resulta imprescindible entonces, en el ámbito de las instituciones que abordan problemáticas vinculadas a nuestro pasado reciente y que implementan exposiciones de artes visuales, iluminar algunos de los mecanismos de funcionamiento inherentes al dispositivo "exhibición" ya que, como veremos, las exposiciones son instancias narrativas cuyo anclaje institucional nunca es neutral (Battiti, 2013, pp. 183-185).

Dedica unos párrafos a analizar el formato de la exposición en tanto discurso, y a la tarea del curador como generador del mismo, detallando de qué se trata el trabajo curatorial en sí y todo lo que conlleva, y manifiesta en tono crítico:

$\mathrm{Ni}$ el discurso curatorial ni el institucional -que pueden tener diferentes grados de coincidencia o tensión entre sí- se generan en campos de acción libres y autónomos sino que operan desde estructuras friccionadas por diversos intereses políticos, económicos y sociales. Las narraciones conectan e interpretan acontecimientos y tanto desde la curaduría de una exposición como desde el trazado de políticas institucionales se ejerce la autoridad -no necesariamente el autoritarismo- de seleccionar, escoger obras u artistas, sucesos o acciones. Lo que me interesa resaltar aquí en relación a las exposiciones es que, tradicionalmente, se ha tendido a ocultar la estructura de poder que las sostiene, presentando el relato visual en cuestión como una "verdad" o como lo que "debe ser", opacando gestos y decisiones que inevitablemente iluminan o borran elementos de la narración (2013, p. 187).

Tras preguntar abiertamente quiénes son los que impulsan este tipo de exposiciones, qué memorias reivindican, cómo se plantean los contenidos, se refiere a la metodología del Parque de la Memoria, que por medio de la presentación de propuestas de exposiciones por parte de la curadora y de la directora al Consejo Directivo se genera el programa según la aprobación de este último. Siguiendo a Didi-Huberman indica que "una exposición no debe tratar de tomar el poder sobre los espectadores sino proporcionar recursos que incrementen la potencia del pensamiento", y concluye expresando:

No obstante, en el marco de una historia reciente y memoria caliente que aún palpita en diversos registros de la esfera social, una práctica curatorial que conciba el formato exposición como una instancia en proceso, abierta y autocrítica se perfila, en mi opinión, como la más apta para genera significaciones e interpretaciones que no descansen en la conformidad de discursos monolíticos (2013, pp. 188-189).

En la bibliografía Battiti alude a los museum studies, y al GEME como "el que se abocó por primera vez formalmente al estudio sistemático de las exhibiciones de artes visuales" (2013, p. 184); además menciona trabajos de tinte regional a cargo de curadores como Marcelo Pacheco, Mari Carmen Ramírez, Justo Pastor Mellado y Cuauhtémoc Medina. 


\section{CIC - Curaduría y Arte. Perspectivas actuales}

En 2012 el Centro de Investigación Cinematográfica (CIC) abre la carrera terciaria de Curaduría y Gestión Cultural. Durante ese año y el siguiente, organiza un ciclo de conferencias sobre curaduría a cargo de la curadora, historiadora de arte y docente Eugenia Garay Basualdo ${ }^{35}$, en el que son invitados a participar Andrea Elías, María Laura Rosa junto al colectivo de artistas Mujeres Públicas, Rodrigo Alonso, Laura Casanovas, Valeria Keller, María José Herrera y Florencia Battiti. En 2014 la institución edita el libro Curaduría y Arte. Perspectivas actuales compilado y prologado por Jorge Zuzulich, y que también cuenta con una introducción de Garay Basualdo. La coordinación de la carrera y el compilador deciden incluir sólo las transcripciones de algunas de las conferencias organizadas: Crónicas Venecianas por Rodrigo Alonso, Mujeres Públicas en la Bienal de La Habana por Mujeres Públicas y María Laura Rosa, y Curaduría y gestión cultural en Salta por Andrea Elías; y también resuelven sumar artículos sobre muy diversas temáticas de otros docentes de la institución y artistas invitados: Maraní González del Solar, Martín Bonadeo, Joaquín Fargas, Andrea Wain y Juan Cruz Andrada. El prólogo a cargo de Zuzulich, profesor de la carrera, se refiere a la figura del curador y su vínculo con la institución-arte; texto que contiene algunas cuantas similitudes con el ya analizado del libro La Trastienda del curador. Además, reseña sintéticamente lo que integra las partes dos y tres de la publicación: una introducción sobre arte contemporáneo, experiencias de artistas, y las visiones de dos docentes sobre las relaciones entre curaduría, gestión, crítica y mercado. El segundo, a cargo de Garay Basualdo, considera el rol del curador, los diversos perfiles "como el historiador de arte, el crítico y el curador formado como tal" (Garay Basualdo, 2014), y la profesionalización indicando que:

Es fundamental comprender que el panorama en el que trabaja un curador es muy amplio y abarca gran diversidad de manifestaciones artísticas de su propia época e incluso anteriores. Es por esto la importancia de su especialización a la hora de enfrentar el reto de cada exposición, festival o evento multidisciplinario que deba realizar. Si bien la experiencia se hace con la práctica, el grado de especialización colabora a la hora de insertarse de manera segura y ágil en el campo del arte (Garay Basualdo, 2014, p. 12).

La curadora comenta los contenidos de cada una de las conferencias transcriptas y de qué manera son considerados como aportes por escrito para el campo curatorial local.

\section{UNTREF - Estudios curatoriales}

En 2009 la Universidad Nacional de Tres de Febrero abre la primera Maestría y Especialización en Curaduría de Artes Visuales con un seminario internacional ${ }^{36}$ de tres días en el que participan curadores del ámbito local y del internacional. A partir de mediados de 2012 comienza a editar la revista electrónica Estudios Curatoriales que depende del Instituto de Investigaciones en Arte y Cultura "Dr. Norberto Griffa" de la UNTREF. En el 
editorial del primer número, denominado Estudios curatoriales, un área de investigación, su directora Diana Wechsler vierte varias definiciones a modo de criterios rectores para configurar el marco teórico en el que se basan estas publicaciones. Plasma su propia definición de las exposiciones, a las que considera "relatos curatoriales":

Construidas con imágenes y otros dispositivos, a partir de una serie de presupuestos teórico críticos e historiográficos, no siempre conscientes o explícitos, comencé a leer los relatos curatoriales como relatos políticos, como narraciones imaginarias, como reconfiguración de memorias, entre algunas de las dimensiones estudiadas en la convergencia de distintas disciplinas, desde la historia del arte, la sociología cultural, los estudios visuales, la historia de las ideas, la teoría del arte, y la historiografía... (Wechsler, 2012, p. 2).

A partir de esta noción fundamenta el planteo de realizar una publicación que se dedica a los “estudios curatoriales". Además se refiere al curador como "el responsable de la producción y circulación de conocimientos nuevos que transitan socialmente por vías diversas" (2012, p. 2), y a la curaduría como:

Una herramienta crítica que si bien está asociada a las artes visuales -desde la historia del arte hasta la práctica artística- puede superar esas fronteras y resultar un instrumento valioso para otros especialistas como antropólogos, sociólogos culturales, museólogos, musicólogos, historiadores, entre algunas de las posibles aproximaciones (2012, p. 2).

La autora observa a la curaduría como una práctica que puede vincularse con diversos "espacios de producción intelectual y social de la cultura" (2012, p. 2), así como "desde los ámbitos de la investigación académica hasta los de la exploración artística, pasando por los espacios de gestión, conservación y reflexión patrimonial” (2012, p. 2). Esta es la primera publicación digital que dice estar dedicada al estudio de la curaduría en el país, pero no siempre se encuentran en sus ediciones con la totalidad de los artículos consagrados a la curaduría. Al contrario, se advierte una pluralidad temática permeable de ser puesta en relación con la práctica curatorial, en ciertas ocasiones, y que atiende a un asunto en particular en cada número incluyendo al coleccionismo ( $\left.n^{\circ} 1\right)$, las bienales ( $\left.n^{\circ} 2\right)$, "pensar con imágenes” ${ }^{37}$ ( $n^{\circ} 3$ ), la literatura, el arte contemporáneo y el arte popular ( $\left.n^{\circ} 4\right)$, arte y memoria ( $\left.n^{\circ} 5\right)$, y arte y tecnología ( $\left.n^{\circ} 6\right)$; dado al recorte temporal de este trabajo se llega hasta 2017. En cada caso un editor invitado se ocupa de reunir los escritos de cada dossier digital, y siempre cuentan con una presentación a cargo de Wechsler. Cabe destacar que en un convenio que formaliza en $2013^{38}$ la Universidad Nacional de Tres de Febrero con el Museo Provincial de Bellas Artes Franklin Rawson de San Juan, se acuerda el dictado de la Maestría en Curaduría de Artes Visuales por primera vez en una provincia que nos sea Buenos Aires. 


\section{UNA - Sobreescrituras}

En 2014 el Área Transdepartamental de Crítica de Artes de la Universidad Nacional de las Artes da inicio a la Licenciatura de Curaduría en Artes. El área cuenta con varias publicaciones electrónicas disponibles en su sitio de internet que involucran a varias de las carreras que impulsa la institución. Sobreescrituras. Diálogos entre teorías, críticas, memorias y experiencias de las artes es una de las revistas digitales que comienza a publicarse en diciembre de 2015. En la edición del verano 2016/2017 se encuentra, en la sección "tema especial", una entrevista denominada Tiempos de curaduría. Todo lo que hasta ahora pensaron sobre la curaduría, por favor, olvídenlo que Rolando Martínez Mendoza y José Luis Petris le realizan al curador Marcelo Pacheco. Además, suma dos artículos sobre curaduría a cargo de Sebastián Vidal Mackinson y Federico Baeza. Sin embargo, esta carrera no cuenta con una publicación específica sobre curaduría que responda al período que se estudia. No obstante, cabe aclarar que en la serie denominada Cuadernos del Instituto. Investigación y Experimentación. Arte y Crítica, se publica de manera electrónica el número dos en agosto de 2018, titulado Paratextos del Arte Contemporáneo ${ }^{39}$. Ésta edición, coordinada por Sergio Moyinedo y Marina Panfili, está dedicada al análisis de textos de catálogos de exposiciones y a prácticas artísticas.

\section{CODA}

En 2008 el Centro Cultural Parque España de la provincia Córdoba organiza un ciclo de reflexión, formación y análisis sobre la curaduría; a la vez, se plantea un examen sobre la producción cordobesa de arte contemporáneo. Se invitan a curadores locales e internacionales como Victoria Noorthoorn, Ticio Escobar, Justo Pastor Mellado, entre otros, que participan en conferencias, talleres, clínicas, y un concurso de proyectos curatoriales. Con la coordinación de la curadora Andrea Ruiz, tanto el ciclo Híbrido y puro. Prácticas curatoriales en el arte contemporáneo del 2008, como el libro electrónico Híbrido y puro ${ }^{40}$ publicado en 2009, que resume toda la actividad y suma aportes teóricos, se convierten en una de las primeras acciones implementadas desde una provincia que no sea Buenos Aires sobre el estudio analítico de la curaduría local. Dado a la magnitud de este libro -116 páginas-, y a que excede la extensión de este trabajo, se toma la decisión teórico-metodológica de no abordarlo. En 2013 la Universidad de El Salvador abre la Especialización en Curaduría de Arte Contemporáneo, y a partir de 2019 también ofrece la Maestría en Curaduría de Arte Contemporáneo; hasta abril de 2018 María del Carmen Magaz dirige ambas, y luego asume en la dirección Alejandro Schianchi, hasta la actualidad. En 2018 esta universidad, con el apoyo de la Fundación Alfonso y Luz Castillo (ArtexArte), edita el libro Curaduría. Una aproximación genealógica, que reúne seis artículos que abordan diversas temáticas con prólogo de Jorge Zuzulich, autor también de uno de los textos. Zuzulich aclara que estos escritos forman parte de la investigación Curaduría: una aproximación genealógica. Génesis, desarrollo, conceptualización y relacionalidad en el campo artístico de Buenos Aires. Dado a que la fecha de publicación de este libro excede este marco temporal, se toma la decisión teórico-metodológica de no analizarlo, pudiendo ser parte de un futuro trabajo. 
Del mismo modo, se da cuenta que se conoce el libro publicado en marzo de 2019 Modelos y prácticas curatoriales en los 90. La escena del arte en Buenos Aires de Jimena Ferreiro, y por el mismo motivo es que no se lo analiza.

\section{Consideraciones finales}

El corpus de publicaciones analizadas permite advertir la existencia de diferentes líneas de trabajo que pueden agruparse de tres maneras. La histórico - crítica que proviene fundamentalmente de la investigación en historia del arte y que puede ejemplificarse con el Grupo de Estudios sobre Museos y Exposiciones (GEME), y la apertura y sistematización del campo de estudio de la historia de las exposiciones. Esto también se distingue en otros autores que publican en diferentes libros sus estudios de casos específicos de exhibiciones. La teórica que se asienta en el tratamiento efectivamente "teórico" que utiliza nociones de la filosofía, la estética, la sociología, la semiótica, la historia del arte y de la cultura, entre otras, para explicar de qué se trata la curaduría y como se desempeña el curador en sus funciones. Esto se aprecia en los textos analizados de Rodrigo Alonso y Jorge Zuzulich, y en los Federico Baeza y Sebastián Vidal Mackinson; y también en otros no abordados en este trabajo como los de Marcelo Pacheco. Y la empírica que refiere al relato testimonial que está basado en la práctica de la curaduría y en el que se pone de manifiesto la "voz del curador" (Herrera, 2009). Esto se observa en el libro Curadores. Entrevistas (2005), y en las publicaciones de ciclos de conferencias, como por ejemplo, La trastienda del curador que organiza la Asociación Argentina de Críticos de Arte. Por lo expuesto, se considera que la contribución que el GEME efectúa es el hito fundacional para la conformación del campo de estudio de la curaduría en la Argentina, ya que inicia una tarea sistemática con un alcance nacional inédito hasta el momento. De otro modo, los aportes desde las distintas líneas de teorización complementan estos estudios, y los amplían generando reflexiones y entrecruzamientos disciplinares. Asimismo, las publicaciones integradas por testimonios comprenden visiones abarcadoras de determinados períodos del arte contemporáneo argentino, y con diversos curadores como protagonistas. Refieren a la práctica misma como un trabajo que integra saberes previamente adquiridos, y la implementación de estrategias que se adaptan al contexto local de las artes visuales según la circunstancia.

Finalmente, se destaca que existen otros tipos de publicaciones dispersas como registros de debates públicos, ponencias, artículos académicos, notas periodísticas y textos de catálogos de exposiciones que también se consideran como documentos que colaboran con la construcción del campo del estudio teórico-crítico de la curaduría, y podrán ser abordados en un futuro trabajo.

\section{Notas}

1. En adelante GEME. 
2. En el 2001 el departamento de investigación del MNBA, a cargo de Herrera, comienza el estudio de los archivos de las exposiciones llevadas a cabo en la institución.

3. En adelante el primer libro del GEME.

4. Realizadas conjuntamente con la Escuela Superior de Bellas Artes Dr. José Figueroa Alcorta y la Asociación Argentina de Críticos de Arte.

5. En adelante el segundo libro del GEME.

6. En adelante el tercer libro del GEME.

7. Revista de Historia del Arte y Cultura Visual del Centro Argentino de Investigadores de Arte.

8. En adelante la cuarta publicación del GEME.

9. Didi-Huberman, G. (otoño de 2010). La exposición como máquina de guerra. Madrid, España: Circulo de Bellas Artes. Recuperado de: http://www.circulobellasartes.com/revis taminerva/articulo.php?id=449

10. Bennet, T. (1995). The birth of the museum. History, theory and politics. London/New York. Routledge.

11. Hooper-Greenhill, E. (1992). Museums and the shaping of knowledge. London/New York. Routledge.

12. Foucault, M. (1970) The order of things. London. Tavistock/Routledge.

13. Crimp, D. (1993) On museum's ruins. Cambridge/London, MIT Press.

14. Duncan, C. (2001) Civilizing rituals, inside public art museum. Londres/New York. Routledge.

15. Didi-Huberman, G. (otoño de 2010). La exposición como máquina de guerra. Madrid, España: Circulo de Bellas Artes. Recuperado de: http://www.circulobellasartes.com/ revistaminerva/articulo.php?id=449

16. El destacado en nuestro.

17. Artista visual y curador de la Galería del Centro Cultural Ricardo Rojas entre 1989-1996.

18. Según consta en el texto: crítica de arte y profesora de historia del arte de la Facultad de Filosofía y Letras (UBA), directora del Museo de Arte Moderno de Buenos Aires 19972013.

19. Según consta en el texto: arquitecto y curador independiente. En Bahía Blanca dirigió el MBA entre 1991 y 2002, y el MAC entre 1995 y 2002.

20. Según consta en el texto: Lic. en Artes (UBA) y curador del Malba desde 2002 (hasta 2013).

21. Según consta en el texto: Lic. en Artes (UBA), profesora de la cátedra Historia del Arte Argentino, Facultad de Filosofía y Letras (UBA) y curadora independiente. Entre 1997 y 2000 curadora del MAMBA. Curadora de Berni y sus contemporáneos. Correlatos. Malba, 2005.

22. Según consta en el texto: artista visual y curador independiente.

23. Según consta en el texto: escritor para ramona; se autodenomina curador ocasional.

24. Se organiza conjuntamente con Fondation Daniel Langlois de Montreal, Canadá.

25. Véase: http://www.roalonso.net/es/arte_y_tec/arte_y_tecnologia.php

26. En adelante AACA.

27. Entre marzo de 2011 y julio de 2016 quien escribe se desempeña como asistente técnica de la AACA y tiene a cargo la organización del ciclo en las ediciones IV, V y VI. Se 
ocupa de grabar, desgrabar y editar las conferencias junto a sus autores. Media entre la AACA y la Fundación Alfonso y Luz Castillo para su publicación. En los créditos figura como asistente editorial.

28. Albano, S. (2007). Michel Foucault. Glosario epistemológico. Buenos Aires, Argentina: Quadrata, y Foucault, M. (2010). El cuerpo utópico. Las heterotopías. Buenos Aires, Argentina: Nueva Visión.

29. Honneth, A. (2007). Reificación. Un estudio en la teoría del reconocimiento. Buenos Aires, Argentina: Katz Editores, y Lukács, G. (1985). Historia y conciencia de clase. Madrid, España: Grijalbo.

30. Bennett, T. (1999). The birth of museum. History, theory, politics. New York, EE.UU.: Routledge.

31. Didi-Huberman, G. (2010a). Ante la imagen. Pregunta formulada a los fines de una historia del arte. Murcia, España: Cendeac; (2010b). La exposición como máquina de guerra. Disponible en: http://www.circulobellasartes.com/ag_ediciones-minerva-Leer-Minerva Completo.php?art=449; (2009). La imagen superviviente. Historia del arte y tiempo de los fantasmas según Aby Warburg. Madrid, España: Abada; (2008). Cuando las imágenes toman posición. El ojo de la historia 1. Madrid, España: Antonio Machado Libros.

32. Tejeda Martín, I. (2006). El montaje expositivo como traducción. Fidelidades, traiciones $y$ hallazgos en el arte contemporáneo desde los años 70. Madrid, España: Trama; (2010) La museografía modernista como dispositivo de domesticación de las vanguardias históricas. Disponible en: http://www.web.unam.es/otros/estetica/DOCUMENTOS\%20EN\%20 PDF/ISABEL\%20TEJEDA.pdf

33. Además participan obras de Alberto Heredia, Juan Carlos Distéfano, Norberto Gómez, Nicola Constantino, Ennio Iommi, Jorge Gumier Maier, Elba Bairon, Omar Schiliro, Cristina Schiavi, Ariadna Pastorini, Marina De Caro, Mónica Van Asperen, María Juana Heras Velasco, Pablo Suárez, Román Vitali, Martín Di Girolamo, Leandro Erlich, Silvana Lacarra, Miguel Harte, Sebastián Gordín, Daniel Joglar, Liliana Maresca, Emiliano Miliyo, Martín Calcagno.

34. En 2014 queda al frente de la cátedra María Laura Rosa y se incorpora Eugenia Garay Basualdo que, desde 2015, se hace cargo hasta la actualidad. En 2016 también asume la cátedra Curaduría II hasta el momento.

35. Docente desde 2012 a la actualidad de las materias Curaduría I, Historia del Arte III y Arte Latinoamericano. Es ex alumna de la carrera de Dirección de Cine con título obtenido en 1999.

36. Véase: http://leedor.com/2009/07/29/curaduria-en-artes-visuales/

37. Número especial dedicado a los textos derivados de las presentaciones realizadas durante el Seminario Internacional convocado bajo el mismo lema, con la participación de los invitados: Didi-Huberman, Aurora Fernández Polanco, Yayo Aznar y Josu Larrañaga, y Graciela Sacco.

38. Véase: https://www.arte-online.net/Notas/Maestria_en_Curaduria_en_Artes_Visua les_de_la_UNTREF_en_San_Juan

39. Véase: https://assets.una.edu.ar/files/file/critica-de-arte/2018/2018-ca-contenidoscuaderno-iieac-nro-2.pdf

40. Véase: http://hipermedula.org/wp-content/uploads/2010/10/hibrido_y_puro.pdf 


\section{Referencias}

Ferreiro, J. (2019). Modelos y prácticas curatoriales en los 90: la escena del arte en Buenos Aires. Buenos Aires, Argentina: Libraria.

Gumier Maier, J. (Ed.). (2005). Curadores. Entrevistas. Buenos Aires, Argentina: Libros del Rojas. Véase: https://www.pagina12.com.ar/diario/suplementos/espectaculos/6-11502005-11-29.html

Herrera, M. J. (Ed.). (2009). Exposiciones de arte argentino 1956-2006. La confluencia de historiadores, curadores e instituciones en la escritura de la historia. Buenos Aires, Argentina: Asociación Amigos del Museo Nacional de Bellas Artes.

(2010). El Museo Nacional de Bellas Artes. Historia, gestiones y curaduría. En R. Amigo y otros. Museo Nacional de Bellas Artes. Colección. (pp. 18-37, vol. II). Buenos Aires, Argentina: Asociación Amigos del MNBA.

(2011). Exposiciones de arte argentino y latinoamericano. Curaduría, diseño y políticas culturales. Córdoba, Argentina: Escuela Superior de Bellas Artes Dr. Figueroa Alcorta; Buenos Aires, Argentina: Grupo de Estudios sobre Museos y Exposiciones.

(2012). El Museo Nacional de Bellas Artes y su proyección nacional, 1911-1943.

En Baldasarre, M. I. y Dolinko, S. (Ed.). Travesías de la imagen II (pp. 529-552). Sáenz Peña: Argentina, Universidad Nacional de Tres de Febrero.

(2012). La trastienda del curador: la crítica en la práctica curatorial. Ciencia y experiencia. Buenos Aires, Argentina: Fundación Alfonso y Luz Castillo.

(2013). Exposiciones de arte argentino y latinoamericano. El rol de los museos y los espacios culturales en la interpretación y la difusión del arte. Buenos Aires, Argentina: Arte $\mathrm{x}$ Arte.

(2014). Cien años de arte argentino. Buenos Aires, Argentina: Biblos - Fundación OSDE

(2017). Historias de exposiciones y sus instituciones: un abordaje complejo de las instancias de significación del arte, las apropiaciones interpretativas de los objetos y sus distintos relatos a través de la historia. Caiana No 10. Recuperado de: http://caiana. caia.org.ar/template/caiana.php?pag=articles/article_2.php\&obj=267\&vol=10

Rosa, M. L. y Babino, M. E. (Ed.). (2013). Diálogos entre la historia, la curaduría, el mecenazgo y la investigación. Buenos Aires, Argentina: Eseade.

Zuzulich, J. (Ed.). (2014). Curaduría y Arte. Perspectivas actuales. Buenos Aires, Argentina: del CIC.

(2018). Curaduría. Una aproximación genealógica. Buenos Aires, Argentina:

ArtexArte.

Abstract: From the 2000's onwards the first, but scarce, physical publications in book format on local curatorship are published. At a time when new institutions dedicated to contemporary art and consequently new collections were emerging, the figure of the curator, although still the subject of controversy, became consolidated both in the institutional 
and independent spheres. This paper analyzes the specific publications on curatorship that have emerged between 2002 and 2017 in Argentina from a critical approach, and attempts to be a contribution to an appreciation of the advances in curatorial studies at the local level.

Keywords: curatorial studies - history of exhibitions - curatorial practice.

Resumo: A partir dos anos 2000, as primeiras, mas escassas, publicações físicas em formato de livro sobre curadoria local são publicadas. Numa época em que novas instituições dedicadas à arte contemporânea e consequentemente novas coleções estavam surgindo, a figura do curador, embora ainda objeto de controvérsia, consolidou-se tanto no âmbito institucional quanto no âmbito independente. Este documento analisa as publicações específicas sobre curadoria que surgiram entre 2002 e 2017 na Argentina a partir de uma abordagem crítica, e tenta ser uma contribuição para uma apreciação dos avanços nos estudos curatoriais a nível local.

Palavras chave: estudos curatoriais - história das exposições - prática curatorial.

[Las traducciones de los abstracts fueron supervisadas por el autor de cada artículo] 